\title{
Performance of Psychiatric Hospital Discharges in Strict and Tolerant Environments
}

\author{
James O. Carpenter, Ph.D.* \\ Norman C. Bourestom, Ph.D.
}

\begin{abstract}
Community mental health professionals are greatly concerned with the type of social environment most conducive to helping patients remain outside psychiatric institutions and improving the quality of their lives in the community. This paper examines the tolerance of deviance characterizing significant others in the patient's environment as it relates to community tenure and selected measures of performance and quality of life of the older patient in the community. A possible role is suggested for differential tolerance of deviance in the lives of patients discharged from psychiatric hospitals. Although it would appear that patients may return to the hospital at a higher rate from low tolerance environments, it may be that for patients who remain in the community, the quality of life may be better in low tolerance environments in terms of social interaction and life satisfaction. The deviance model is of value in the continuing efforts to understand the role of the social environment in the community life of discharged patients.
\end{abstract}

The trend to move mental patients from psychiatric hospitals into the community has increased concern about the type of social environment most conducive to helping patients remain outside psychiatric institutional walls and for enhancing the quality of their lives in the community. The deviance model offers one approach toward studying this issue. This model emphasizes the adverse social reaction to certain behaviors, including the imputation of "deviance" to the person showing that unusual behavior.

Lemert $(1951,1967)$ holds that there are two types of deviance, primary and secondary. In the instance of primary deviance, the person is able to integrate his unusual behavior into a role that his family and friends regard as normal. Secondary deviance, on the other hand, entails the organization of the behavior into a role that is regarded as deviant. A number of writers (Gove, 1970; Fletcher \& Reynolds, 1968) have applied these concepts to the mental illnesses. Scheff (1966), for example, considers psychiatric symptoms and signs as violating social norms, and suggests that stable mental illness may be regarded as a deviant social role. This perspective, in turn, suggests the importance of the social environment of the patient discharged from the psychiatric hospital, with its possibilities for keeping the patient in the community and improving his existence by doing so.

${ }^{*}$ Dr. Carpenter, a sociologist, as Assistant Professor of Health Behavior and Associate Director, Program in Health Gerontology. The University of Michigan School of Public Health, Ann Arbor, Michigan, 48104. Dr. Bourestom, a psychologist, is Unit Psychologist, Veterans Administration Hospital, St. Cloud, Minnesota. Appreciation is extended to Dr. Charles $M$. Wylie of the University of Michigan School of Public Health for reviewing an earlier version of this paper. 
The willingness of family and friends to tolerate unusual behavior may be one aspect of the patient's social environment that is important in achieving success in the community. For example, it has been found (Freeman \& Simmons 1958, 1963; Simmons \& Freeman, 1959) that married male discharges were functioning at a higher level than unmarried men. They interpreted this finding to mean that wives forced their husbands after hospital discharge to eliminate some deviant behavior, whereas mothers and other social contacts of the unmarried were more tolerant of unusual behavior. Dinitz and his associates found support for this interpretation in their own study of posthospital performance (Dinitz, Lefton, Angrist and Pasamanick, 1967).

In assessing the social reaction to the mental illnesses, the essential elements are social control and varying ability of family and friends or "significant others" to tolerate deviant behavior. This paper examines the relationship between the differential tolerance of deviance and selected performance measures of older patients discharged from a psychiatric hospital. Community tenure, that is, whether patients remained in the community or returned to the hospital, is only one measure of performance that will be examined in this study. Just as significant is the quality of life of the ex-mental patient in the community. Social activities, instrumental performance, and life satisfaction are other factors that will be examined in assessing the possible implications of differential tolerance of deviance for the performance of ex-patients in the community and for the quality of their lives.

\section{STUDY POPULATION AND PROCEDURES}

Data were collected for 78 patients discharged to a number of community settings from a state psychiatric hospital. Most had been diagnosed as having schizophrenia, and had been in the hospital for an average of 17 years. They thus formed an elderly group with an average age of 65 years. All patients had been actively engaged in a program of milieu therapy prior to their community discharge.

Information about differential tolerance of deviance was collected through interviews with the significant others of patients using items similar to those of Freeman and Simmons (1963), which call for a description of symptomatic behavior. The list was prefaced by the following statement: "Now let me read you a list of statements which people have made regarding the behavior of former mental patients. "This was followed by such items as appearing in a daze, talking without making sense, and hearing noises. For each item, the significant others were asked to indicate what they would do if the expatient acted in the manner described. Their responses were then classified as being highly tolerant, moderately tolerant, or essentially intolerant. The series of responses were combined to form three average levels of tolerance in the social environments of the patients.

Included as posthospital outcomes were the following items: 
1. Community tenure: Questions were asked as to whether the patient remained in the community or returned to the hospital in the 12 months following discharge.

2. Social participation: Questions were asked about each patient's involvement in hobbies, talking with others, and in various recreational and other social activities. An eight-point social performance scale was constructed to classify each patient.

3. Life satisfaction: Each patient was asked six items, dealing with his satisfaction with his present life, his current state of happiness, how often he felt lonely, and whether or not he felt things were better than he had expected they would be (scale of $0-12$ ).

4. Levels of instrumental performance: This was determined by asking about the patient's involvement in doing chores, going shopping, taking care of money and other instrumental tasks. Patients were classified on a five-point scale of instrumental performance.

All study patients were actively involved in a program of milieu therapy prior to discharge. Moreover, patient age was unrelated to the tolerance setting to which patients were discharged.

\section{FINDINGS}

Table 1 presents the findings, which suggest that the differential tolerance of deviance separates patients who remained in the community from those returning to the hospital. Whereas 34 percent of patients in low tolerance settings returned to the hospital in the year following release, this was the case for only $13 \%$ of those in highly tolerant environments. These data suggest the importance of tolerance of deviance of significant others for the community careers of ex-patients. A case in point is the reason given for returning one patient to the hospital: "I couldn't stand to watch her. She mumbled and rambled on about nonsense. I couldn't sleep thinking about her." In marked contrast was the situation of a patient in a highly tolerant environment. She constantly chanted that others were eating her face away. She also held all-night conferences with dead relatives. When asked why the patient had not been rehospitalized, the interviewee responded: "Why should she be?"

\section{TABLE 1}

Community Tenure of 78 Patients Discharged from Mental Hospital, by Ability of Significant Others to Tolerate Deviant Behavior

\begin{tabular}{|c|c|c|c|c|c|c|}
\hline \multirow{3}{*}{ Tolerance of Deviance } & \multirow{2}{*}{\multicolumn{2}{|c|}{ Total }} & \multirow{2}{*}{\multicolumn{2}{|c|}{$\begin{array}{l}\text { Commu } \\
\text { Remained in } \\
\text { Community }\end{array}$}} & \multirow{2}{*}{\multicolumn{2}{|c|}{$\begin{array}{l}\text { ty Tenure } \\
\text { Returned to } \\
\text { Mental Hospital }\end{array}$}} \\
\hline & & & & & & \\
\hline & Number & $q$ & Number & $\frac{6}{6}$ & Number & 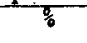 \\
\hline High Tolerance & 46 & 100.0 & 40 & 87.0 & 6 & 13.0 \\
\hline Low Tolerance & 32 & 100.0 & 21 & 0.5 .6 & 11 & 34.4 \\
\hline
\end{tabular}


TABLE 2

Average Social Participation Scores of 61 Patients One Year After Release from Mental Hospital by Ability of Significant Others to Tolerate Deviant Behavior

\begin{tabular}{|l|c|c|c|}
\hline & & \multicolumn{2}{|c|}{ Social Participation Sicores } \\
\hline Tolerance of Deviance & Number & Mean & S.v. \\
\hline High Tolerance & 20 & 2.90 & 1.83 \\
Moderate Tolerance & 20 & 3.65 & 2.23 \\
Low Tolerance & 21 & 4.76 & 2.20 \\
\hline F $=4.116$ & $\mathrm{p}<.025$ & & \\
\hline
\end{tabular}

Note.-Patients scored on scale 0-8, with 8 indicating maximum social participation.

Table 2 presents the relationship between differential tolerance of deviance and the social participation of the patients. Those in a low tolerance environment had the highest social participation score. Those in the high tolerance settings had the lowest scores, whereas those in moderate tolerance environments had intermediate scores. These data suggest that the high demands for socially appropriate behavior in low tolerance settings may be reflected in higher social performance levels among ex-patients.

A comparable picture emerges with respect to instrumental performance in Table three, although the differences are not statistically significant. There is a trend for patients in low tolerance settings to function at the higher level of instrumental activities than do patients in more tolerant environments.

\section{TABLE 3}

Average Instrumental Performance Scores of 61 Patients One Year After Release from Mental Hospital by Ability of Significant Others to Tolerate Deviant Behavior

\begin{tabular}{|l|c|c|c|}
\hline \multirow{2}{*}{ Tolerance of Deviance } & \multicolumn{2}{|c|}{ Instrumental Performance } \\
& Number & Mean & S.D. \\
\hline High Tolerance & 20 & 2.10 & 1.62 \\
Moderate Tolerance & 20 & 2.70 & 1.75 \\
Low Tolerance & 21 & 3.10 & 1.51 \\
\hline F $=1.934$ & & & \\
\hline
\end{tabular}

Note.-Patients scored on scale 0-5, with 5 indicating maximum instrumental performance. 
The findings for life satisfaction are presented in Table Four. The low tolerance environment was accompanied by significantly higher life satisfaction scores. Thus patients in low tolerance environments not only evidenced higher levels of performance in social and instrumental activities, but were also more satisfied with their lives.

Finally, it should be noted that the relationships between differential tolerance of deviance and the functioning of ex-patients in the community 1 year following discharge do not appear to reflect merely the return of low-score patients to the hospital. The social and instrumental functioning scores of patients returning to the hospital are very similar to those of ex-patients remaining in the community; for example, patients returning to the hospital had an average social participation score of 3.57 compared to 3.76 for those remaining in the community. This situation also holds with respect to instrumental performance. Moreover, it is worth noting that tolerance of deviance and the ages of discharged patients are not related and that sex, length of hospitalization, and education did not differentiate the performance and life satisfaction levels of the discharged patients remaining in the community.

\section{DISCUSSION AND CONCLUSIONS}

This paper suggests a possible role for differential tolerance of deviance in the lives of patients discharged from psychiatric hospitals. Although it would appear that psychiatric hospital discharges may return to the hospital at a higher rate from low tolerance environments, it may be that for the patients who remain in the community, quality of life may be better in low tolerance environments, at least in terms of social interaction and life satisfaction.

The findings of this study deal with an older population that has been institutionalized for a considerable period of time. Whether these findings

\section{TABLE 4}

Average Life Satisfaction Scores of 58 Patients One Year After Release from Mental Hospital by Ability of Significant Others to Tolerate Deviant Behavior

\begin{tabular}{|l|c|c|c|}
\hline \multirow{2}{*}{ Tolerance of Deviance } & Number & \multicolumn{2}{|c|}{ Life Satisfaction Scores } \\
Mean & S.D. \\
\hline High Tolerance & 19 & 6.10 & 3.09 \\
Moderate Tolerance & 18 & 8.39 & 2.72 \\
Low Tolerance & 21 & 8.24 & 3.06 \\
\hline F $=3.520$ & $\mathrm{p}<.05$ & & \\
\hline
\end{tabular}

Note.-Patients scored on scale $0-12$, with 12 indicating maximum 1 ife satisfaction. 
will be demonstrated in younger groups with shorter institutional experiences is of interest. The findings (Freeman \& Simmons 1958, 1963); Simmons \& Freeman, 1959) regarding male psychiatric discharges tend to indicate that these findings have some generalizability. Noting that married male discharges were functioning at a higher level than unmarried men, they suggest that wives force their husbands after discharge to eliminate some deviant behavior, whereas mothers and other social contacts of the unmarried were more tolerant of unusual behavior. The findings of Freeman and Simmons and those of the present study present interesting points of departure for further investigation. The present study, for example, suggests the need for more detailed investigation and discussion of the deviance perspective. Although other explanations are tenable, it is possible that when subjected to a low tolerance social milieu, the patient is urged to redefine his behavior from secondary deviance, an abnormal role, to primary deviance in which he incorporates his idiosyncracies into a normal social role. Thus the low tolerance environment may provide a set of norms with explicit directions for action. Patients who can conform to these norms may, in turn, learn to integrate the expected behavior into their notion of self.

The deviance model and some of the findings in this paper may also be of use in understanding the role of the social environment in the success and failure of persons with other conditions, for example, physical impairments. New, Ruscio, Priest, Petritsi and George (1968), for instance, note the different reactions of significant others to the stroke patient, and suggest that differential interpretations of patient dependence may be important in the patient's adjustment to stroke. It is possible, then, that patients with disabilities living in settings in which family and friends are.highly tolerant of their dependency may perform at lower levels than those patients with less tolerant significant others.

Larger, longitudinal studies that focus on general populations are clearly needed if we are to come to a better understanding of the role of differential tolerance of deviance in the careers of mental patients. The differential tolerance of deviance is a concept that needs much more study, debate, and practical action, if possible, as the trend continues to maximize the quality of life of the mental patient in the community.

\section{REFERENCES}

Dinitz, S., Lefton, M., Angrist, S. and Pasamanick, B. Psychiatric and social attributes as predictors of case outcome in mental hospitalization. In T. Scheff (Ed.) Mental illness and social processes. New York: Harper \& Row, 1967.

Fletcher, C., \& Reynolds, L. Residual deviance labeling, and the mentally sick role: A Critical review of concepts. Sociological Focus, 1968, 1, 9-27.

Freeman, H., \& Simmons, O. Wives, mothers, and post-hospital performance levels. Social Forces, 1958, 37, 153-159.

Freeman, H., \& Simmons, O. The mental patient comes home. New York: Wiley, 1963.

Gove, W. Societal reaction as an explanation of mental illness: An evaluation. American Sociological Review, 1970, 5, 873-884. 
Lemert, E. Social pathology. New York: McGraw-Hill, 1951.

Lemert, E. Human deviance, social problems and social control. Englewood Cliffs, N. J.: PrenticeHall, 1967.

New, P., Ruscio, A., Priest, R., Petritsi, P. and George, L., The support structure of heart and stroke patients: A study of the role of significant others in patient rehabilitation. Social Science and Medicine, 1968, 2, 185-200.

Scheff, T. Being mentally ill: A sociological theory. Chicago: Aldine, 1966.

Simmons, O., \& Freeman, H. Family expectations and post-hospital performance of mental patients. Human Relations, 1959, 12, 233-242. 